\title{
Faculty Modeling Co-Teaching and Collaboration Practices in General Education and Special Education Courses in Teacher Preparation Programmes
}

\author{
By Leila Ansari Ricci* \\ Joan C. Fingon ${ }^{\dagger}$
}

\begin{abstract}
As increasing numbers of students enter $K-12$ schools with varied learning needs, one viable option to address their needs is through co-teaching or pairing of general and special education teachers in the same classroom to help all students learn. This paper describes one general and one special education professor's first time experience modeling collaboration and co-teaching practices in their respective graduate reading courses at a large, urban, public university in Southern California, USA. Graduate students from both classes observed co-teaching modeled by their professors and participated in workshop sessions including PowerPoint presentations, videos, and small group activities to promote students' understanding of collaboration and co-teaching skills. Students also developed a co-teaching lesson plan in collaboration between general and special education partners. Data sources included faculty ratings of co-teaching lesson plans, students' evaluations of workshops, and students' written reflections of their overall experience. Findings suggest that open communication, willingness to participate, being flexible, and faculty modeling coteaching approaches were among the key factors for effective co-teaching and collaboration.
\end{abstract}

Keywords: co-teaching, collaboration, general education, special education, teacher education preparation programmes.

\section{Introduction}

Within the teaching profession, the need to address the ongoing diverse educational and behavioural needs of students in K-12 classrooms has changed over time for a variety of reasons. In the United States (U.S.), the onset of No Child Left Behind (NCLB, 2001), and more recently the Common Core State Standards Initiative (CCSSI, 2014), have influenced public schools by requiring more accountability for all students. Another U.S. federal mandate, the reauthorisation of the Individuals with Disabilities Education Improvement Act (IDEIA, 2004) emphasised inclusion of (providing support/services to students with disabilities in the least restrictive environment) and maximum access to general education for all children with disabilities. Essentially, more students with disabilities than ever before are being taught in general education classrooms,

\footnotetext{
* Associate Professor of Special Education, California State University, USA.

${ }^{\dagger}$ Professor of Education and Reading, California State University, USA.
} 
with more access to the same curriculum as their peers without disabilities (Magiera, Smith, Zigmond, \& Gebauer, 2005). Classroom teachers also serve more populations of culturally and linguistically diverse students whose performance consistently lags behind that of their native English speaking peers (August \& Shanahan, 2006). Adding further the effects of poverty, social inequity, and lack of access to quality education for all children, the achievement gap among U.S. students continues to widen (Strunk \& McEachin, 2014). However, what remains unknown is the effect of the Every Student Succeeds Act (ESSA, 2015) on schooling as the federal law shifts accountability provisions from the U.S. government to individual states. Given this context, the field of teaching has become more complex, as educators must work more strategically to meet the diverse learning needs of all students. Likewise, in this time of inclusion and educational accountability at federal, state, and local levels, more teachers are working in diverse settings with a range of other professionals (Tröhler, Meyer, Labaree, \& Hutt, 2014), thereby necessitating that schools enhance collaborative efforts between general educators (GE) and special educators (SPE) to help all students achieve. Further, there is a renewed interest in coteaching and the process of collaboration and co-teaching in K-12 schools (Friend, 2015/2016).

In an effort to model co-teaching for future general and special education teachers, this study was conducted at a large, diverse, urban, 4-year public university in Southern California during an 11-week winter quarter in 2015. The study describes the experiences of two higher education faculty members (one SPE professor and one GE professor) teaching reading instruction and assessment courses to graduate students in their respective teacher preparation programmes. It explains the initial collaboration, co-planning, and co-teaching in the two professors' graduate reading courses, along with data analysed from their students to document this overall experience.

\section{Literature Review}

Typically, GE and SPE teachers are paired together in K-12 general education classrooms to co-teach with the goal of more effectively differentiating instruction to meet all students' needs. Murawski (2010) views collaboration as "a style of interaction in which two or more professionals work together toward a common goal," whereas co-teaching is described as "two or more educators who co-plan, co-instruct, and co-assess a group of students with diverse needs in the same general education room" (p. 11). Co-teaching also involves knowing what co-teaching approaches or models (e.g. station teaching, parallel teaching, alternative teaching, team teaching, or one teach/one assist) to use when planning co-taught lessons (Cook \& Friend, 1995). Thus, teaching all students more often requires two or more highly qualified educators who show commitment and willingness to create a positive collaborative partnership (Friend $\&$ Cook, 2007) through acquired knowledge and skills that develop effective collaboration (Fennick \& Liddy, 2001). 
Although there is some evidence in the literature indicating the benefits of co-teaching for students, the "studies reveal a lack of training regarding this service delivery model" (Murawski, 2010, p. 2). Ideally, ensuring that teachers know what and how to implement various co-instructional approaches successfully requires school district-wide training at the very least. Likewise, higher education faculty in teacher preparation programmes can train GE and SPE teacher candidates in the important skills of collaboration and co-teaching, particularly in critical content areas such as reading and language. While coteaching exists and is practiced in K-12 schools, more training on how to effectively use collaboration skills and co-teaching techniques is still needed (Murawski, 2010; Friend, 2014). More importantly, there is growing need for and evidence of such teaching practices occurring in GE and SPE teacher preparation programmes (Bakken, Clark, \& Thompson, 1998; Bacharach, Heck, \& Dahlberg, 2008; Graziano \& Navarrete, 2012; Hudson \& Glomb, 1997; Kluth $\&$ Straut, 2003). Since the benefits of co-teaching are many - pairing two highly qualified teachers to arrange together their different areas of expertise in one classroom for the benefit of students with diverse needs (Snell \& Janney, 2000) - it seems reasonable that higher education faculty would collaborate, explicitly teach, and model these skills and techniques in their respective GE and SPE teacher preparation programmes. While university students seeking SPE licensure often receive instruction in co-teaching, their GE counterparts could benefit from such training as well (Friend, Cook, Hurley-Chamberlain, \& Shamberger, 2010). Moreover, if co-teaching is to take place between two professionals in different interdisciplinary fields, it seems reasonable that both groups of teacher candidates should have opportunities to learn such training in both teacher preparation programmes. Therefore, one practical way to prepare K-12 educators for teaching all children would be to support and increase opportunities for faculty in GE and SPE teacher preparation programmes to model co-teaching. In other words, showing teacher candidates to "do as we say, and as we do" (Kluth \& Straut, 2003, 228).

\section{Methodology}

This descriptive study used a mixed method approach. Data collection consisted of student surveys related to the effectiveness of the co-teaching workshops presented, GE and SPE faculty evaluating students' co-teaching lesson plans, and analysing written reflections from students' overall coteaching and collaboration experience. Student workshop survey data was analysed using SPSS and collated using mean scores for both classes combined. Professors also scored students' co-teaching lesson plans based on a rubric. Written reflections were also analysed. 


\section{Research Questions}

The study was guided by these central questions: 1 . What were the experiences and lessons learned by both GE and SPE professors in their firsttime endeavor of co-teaching and collaboration? 2. What perceptions and experiences did graduate students have in the co-teaching workshops and activities, implemented by both professors to assist them in developing knowledge and skills they need in order to co-plan and collaborate as current or future GE and SPE teachers?

\section{Participants}

Thirty-four students combined were enrolled in two different graduate level courses, consisting of 29 females, 5 males, with an average age of 32 years. Eighteen students were Hispanic, 7 Caucasian, 6 Asian American, one African American, and 3 students who identified themselves as multi-racial. Fourteen students were enrolled in SPE credential/master's programmes, while 20 students were enrolled in a master's degree programme in reading. Twelve were graduate students (not currently teaching), ten GE classroom teachers, three intern SPE teachers, seven paraprofessionals (teacher assistants) and two were substitute teachers. Both faculty members were also participant observers.

\section{Procedures}

The partnership began with an acceptance of a proposal written by both professors for a teaching award from the college's curriculum committee. These competitive grants were designed as a way to motivate faculty to collaborate across the various divisions, programmes, and disciplines. Initially, both professors discussed their own teaching philosophy and past experiences (positive and negative) about co-teaching and collaboration between GE and SPE teachers to get acquainted.

The following events or procedures were employed by the professors: 1 . co-planning of scheduling, agenda items, content, and resources for the workshops in both courses, 2 . modifying course syllabi and co-planning activities reorganised to accommodate for additional content while still maintaining respective programme and state competencies for classes in each programme, and 3. coplanning and co-assessing a modified lesson plan template to be used by GE and SPE students to co-plan differentiated reading instruction for diverse learners in K-12 classrooms. Scheduling deadlines for students' co-teaching lesson plan assignments, grading rubric, and how to weigh and grade each assignment were also co-arranged by both professors. Communication was a combination of face-to-face, phone, and predominantly via email correspondence. Each professor also undertook other tasks and alternated taking responsibility for photocopying and finding resources, etc. 
Four workshops were scheduled and co-taught on different nights in each class; the SPE course was taught on Tuesday, and the same content was taught in the GE course on Wednesday throughout the quarter. Topics included speaking/ using the same terminology, establishing a co-teaching partnership, presenting co-teaching models and co-assessments, and student co-teaching lesson plan presentations. The co-taught sessions were guided by modeling Murawski's (2010) framework of co-planning, co-teaching, and co-assessing, focusing on more effectively differentiating reading instruction for diverse learners. A combination of co-teaching approaches was modeled during 45-minute workshop sessions. Each workshop started with a PowerPoint presentation on a specified topic of co-teaching, followed by a discussion of practical applications to K-12 teaching, in-class small group activities, written reflections, and handouts. GE and SPE student comments from group activities were documented and shared in each class showing their different perspectives of the same material. Students in both classes completed a workshop evaluation after each session.

The culminating assignment was SPE and GE students from each class assigned as partners or a triad, to create a co-teaching reading lesson plan to meet the differentiated learning needs of students. Students had to co-plan a reading lesson utilising different approaches of co-teaching that were introduced and modeled during the workshops. Students were allowed to choose the reading topic, materials, standards, and grade levels for their lesson. They were required to use a template and address the specific needs of three hypothetical students: one with mild/moderate disabilities, one English language learner, and one gifted and talented student in their lesson. A sample lesson and rubric to assist them in creating their co-teaching lesson plans were also provided. Additionally, students were required to document their interactions and collaboration with their partner during co-planning.

The framework of the experience was based on six practical models or approaches of co-teaching commonly cited in the literature based on co-teaching conceptualised by Friend and Cook (2007). These approaches include: 1. one teach/one observe, 2. one teach/one assist, 3. parallel teaching, 4. station teaching, 5. team teaching, and 6. alternative teaching. Faculty modeled these approaches, including the roles and responsibilities of each teacher and the pros and cons of each co-teaching approach, emphasising the goal to maximise the use of both teachers' knowledge and expertise for the benefit of all their students (Murawski, 2010). The need to implement the most appropriate co-teaching approach in reading lessons was also stressed to meet students' needs.

During the workshops, both professors modeled the one teach/one assist approach, and depending on who was the professor of record for that night's class, one took the lead role (content) and the other took the assisting role. Team teaching was also employed during the PowerPoint presentations by taking turns sharing different perspectives on a topic before moving into brief partner discussions (think-pair-share) or small group activity when both professors assisted students to extend or reinforce the lesson (parallel and station teaching). Videos and case study scenarios were also presented in class of co-teaching models and the advantages and disadvantages of using such approaches in co- 
teaching were discussed with students.

\section{Results}

Both classes after each workshop were asked to evaluate and rate the session (ratings: $1=$ strongly disagree to $4=$ strongly agree). Students were asked three questions based on how the workshop increased their knowledge, usefulness/ practicality, and effectiveness of professors delivering the content. Results of combined SPE and GE class average means were slightly higher $(3.79,3.84$, 3.88 ) respectively on item 3 regarding instructor's effectiveness at teaching the content across the sessions. Mean scores slightly increased for all three items after each subsequent workshop session. The final workshop was not evaluated. See Table 1 for the results of the workshop evaluations.

Table 1. SPE and GE Student Combined Workshop Means

\begin{tabular}{|l|c|c|c|}
\hline Item & $\begin{array}{c}\text { Session \# } \\
\mathbf{1} \\
\text { Mean (std } \\
\text { dev) }\end{array}$ & $\begin{array}{c}\text { Session } \\
\begin{array}{c}\text { Mean } \\
\text { (std dev) }\end{array}\end{array}$ & $\begin{array}{c}\text { Session } \\
\mathbf{\# ~ 3} \\
\text { Mean } \\
\text { (std dev) }\end{array}$ \\
\hline $\begin{array}{l}\text { 1.This session increased my knowledge about the } \\
\text { topic }\end{array}$ & $3.44(.66)$ & $\begin{array}{c}3.69 \\
(.47)\end{array}$ & $\begin{array}{c}3.82 \\
(.39)\end{array}$ \\
\hline $\begin{array}{l}\text { 2.Information in session was practical and useful for } \\
\text { my current or future role as general educator/ } \\
\text { special educator }\end{array}$ & $3.50(.71)$ & $\begin{array}{c}3.69 \\
(.54)\end{array}$ & $\begin{array}{c}3.76 \\
(.49)\end{array}$ \\
\hline $\begin{array}{l}\text { 3.Overall, the instructors were effective at } \\
\text { teaching the content of this session }\end{array}$ & $3.79(.59)$ & $\begin{array}{c}3.84 \\
(.37)\end{array}$ & $\begin{array}{c}3.88 \\
(.33)\end{array}$ \\
\hline
\end{tabular}

Students were also asked to openly comment on the surveys after each workshop session. General comments included how much time it takes to collaborate and co-teach, that it cannot be forced upon someone, and that it is important to all be on "the same page", and learning about disabilities and how to adapt reading lessons as vital for meeting the varied learning needs of children. The graduate students also mentioned that support from administration was critical, that co-teaching can increase the potential to produce better student outcomes, and being flexible and willing to try again is essential even if previous experiences were unfavourable. Many students noted that observing faculty modeling of co-teaching increased their knowledge and provided them with practical and useful information for their roles and different perspectives as current or future GE and SPE teachers. One SPE student stated, "I learned about frames of reference and how important it is to talk with the co-teacher to work things out and plan together." Students also mentioned the different co-teaching approaches and resources that were provided during the workshops and how they might incorporate these ideas in their lessons. One GE student wrote, 
While I have learned about the co-teaching models before, I never thought about how I would use them for reading instruction. I like the idea of station teaching since I would be able to address the needs of more students with a co-teacher than by myself, plus it would be a good opportunity to allow for student choice in reading materials.

Clearly, taken all together, these comments indicate a much richer understanding and perspective of how GE and SPE teachers can collaborate and co-teach to meet the reading needs of children in K-12 grades.

The professors assessed students' co-teaching reading lesson plans using a rubric (ratings: 1 to $3 ; 3=$ exceed standards, $2=$ meets standards, and $1=$ below standards). All students either met or exceeded the standards with an average rating of 2.34. Students described appropriate strategies for the three hypothetical students in their lessons and suggested a variety of co-teaching approaches based on the grade level they had chosen. The lesson plans students designed for primary grades included a combination of co-teaching approaches (i.e. station teaching, team teaching, and alternative teaching), while lesson plans developed for older elementary grades included combinations of one teach/one assist, team teaching, and parallel teaching. Interestingly, a few partners who were teaching full time volunteered to revise previous lessons they had taught in their own classes into co-teaching lessons with their partner, integrating various co-teaching approaches for their own classroom.

Students were also asked to rate the overall experience of creating their coplanning lesson on a scale of 1 to $10(1=$ lowest; $5=$ average, $10=$ highest $)$. The average rating was 8.62. Partners who communicated more face-to-face appeared to give higher ratings and thus had a more positive experience. However, GE students rated their experience slightly higher overall than those enrolled in the SPE class, and a few triads (three students together) gave lower ratings, citing a lack of communication as a challenge with their partners.

Final written reflections about students' overall experience were also analysed by both professors to ascertain if there were any differences between GE and SPE students. For example, many SPE students were simultaneously employed as full-time teachers (or as teacher's assistants) while pursuing alternative certification and had more experience, both positive and negative, involving collaboration and co-teaching in their schools. However, most GE students who were not teaching full time had less experience and less confidence about co-teaching and collaboration. These findings could be attributed to the nature of SPE teachers' duties related to inclusion of children with disabilities, as they typically work in GE classrooms, and not the other way around. Overall, the majority of GE and SPE students believed the greatest reward was "sharing and exchanging of ideas," "seeing co-teaching modeling in practice," and being "open to new ideas to benefit students and improve classroom instruction for students with reading disabilities." These data suggest that the co-planning lesson assignment for students enrolled in GE and SPE teacher preparation classes might benefit higher education faculty across programmes working together to model collaboration and co-teaching practices that can be 
applied to graduate students' K-12 teaching.

\section{Discussion}

As professors conducting this study for the first time, this experience taught us several things. Firstly, we gained an understanding of how much real time and effort this project takes. One possible reason for our success was that we established time to collaborate and commit to planning together. We entered our collaboration openly and willingly prioritised time necessary for co-planning with some limitations. Second, we communicated in a variety of ways: meeting face-to-face for 30 to 90 minutes or more, exchanging brief phone calls, and corresponding weekly and/or daily in over 40 email exchanges. Moreover, while co-planning and also teaching other classes in our respective divisions was a challenge, the benefits clearly were meaningful and warrant other teacher preparation and/or graduate faculty to model co-teaching practices for K-12 teachers. Our observations of students' comments and participation in class discussion and activities also fueled our enthusiasm, creating a positive experience. However, we also acknowledge that faculty at other institutions might have different logistical challenges to overcome in order to begin such a project and model co-teaching practices for GE and SPE students in their programmes.

We also learned to accommodate for university course enrollment. For instance, when creating assignments for graduate students that require coplanning or co-teaching that mirror the work of K-12 GE and SPE teachers, there typically are different number of university students enrolled in both GE and SPE courses. Therefore, it may be necessary (as was in our case) to place students in triads rather than pairs for co-planning activities. However, there is a need to provide more support for triads of students to help them better define and distribute their roles and responsibilities and to develop contingency plans that involve students who drop out, have difficulty communicating, and so on. There is also a need to respond to and clarify directions for assignments with students from both professors' courses by 'checking in' and providing consistent feedback.

We also recognise that this type of collaboration is a departure for most higher education faculty who are accustomed to making decisions on their own related to their own courses, but true modeling of collaboration requires taking into consideration another professor and the needs of his/her students. Additionally, we learned the importance of seeking out administrative college/ department support early on. Having both GE and SPE faculty and administration (e.g. department chairs and college dean) increase their commitment to faculty collaboration can build connections between programmes and professors that improve co-teaching and collaboration opportunities. Without this support, the co-teaching experience may not have been as successful or meaningful to us or for our students.

More importantly, we learned about the connections and differences between 
our two programmes as well as our own and our SPE and GE students' perceptions regarding frame of reference, teaching philosophy and pedagogy, and co-teaching and collaboration throughout the experience. Both of us clarified with each other our understanding (and sometimes misunderstanding) of our goals and activities for the students. We also shared with our students our process of communication and flexibility to model for them the effort and skills required in making collaboration and co-teaching work in classrooms, whether at the university or K-12 levels. We reflected upon and described our own professional growth as professors, particularly as we reviewed transcripts of our email exchanges in which there was a noticeable shift in how we ourselves moved from viewing "my students" and "my course" and "your students" and "your course" to a different point of view of "our students" and "our courses" to talk about our work. This was powerful evidence of how we ourselves evolved as professors, as a result of our own experiences working together that was reinforced by modeling co-teaching in each other's classes and interacting and observing our students together. In essence, our faculty modeling for our students about how we learn about each other's philosophy and programmes with flexibility and openness - and how we view all students as "our" students - allowed them to carry such practices and possibilities into their own teaching as K-12 general and special educators.

Engaging in the minutiae of faculty co-teaching - when most professors are accustomed to teaching solo and in their own college, programme, or discipline - can be challenging. However, one important unexpected outcome was that discussing our experiences with other professors informally and in committee meetings strengthened our motivation for and our confidence in coteaching. It is through identifying and sharing stories with other professors who have been successful at co-teaching that furthers the impetus and inspiration for faculty collaboration within and across interdisciplinary courses despite the logistical challenges and/or additional workload.

One area that needs further exploration is analysing what co-teaching approaches are most effective for SPE and GE teachers working with K-12 students with diverse learning needs at different grade levels and in different settings. Modeling collaboration and co-teaching on the part of higher education faculty in our urban setting might be different in other programmes and settings. Additionally, training in SPE and GE programmes for a myriad of professionals in inclusive settings might also improve the support of students with disabilities. As in K-12 schools in which the administrator's role is critical for co-teaching success (Murawski \& Dieker, 2013; Villa, Thousand, \& Nevin, 2013), so is the support of the university administration in facilitating and nurturing such coteaching practices among higher education faculty. Another area of research to pursue is the impact of teacher candidates who were trained in co-teaching practices in teacher training programmes and if or how they are implementing such co-teaching strategies in their schools.

While our experience was not ideal, it was effective on many levels. Students' survey ratings and comments indicated that the co-teaching workshops were a positive and beneficial learning experience in both classes. We also modeled 
for our students consistently using common language, open communication, agreement on sharing duties, and support for each other throughout our collaborative process. Moreover, we shared our work in progress with the broader faculty community in the college through special meetings organised by the college dean. Our findings, though limited, are nevertheless important contributions to the field based on our rich descriptions and documentation of our co-teaching and collaboration practices and mindful experiences from our classes. More importantly, they promote and support professional conversations that initiate change in instructional co-teaching practices and educational outcomes in teacher preparation programmes that assist teacher candidates with helping all children learn.

\section{Conclusion}

The purpose of this study was to document the experience of two professors' first-hand experience as a way to learn from and model for and simulate some of the real challenges and rewards that GE and SPE teachers face in working together in K-12 schools with diverse students. Based on survey results and written comments, the university students found the overall experience favourable and felt that the faculty was highly effective at delivering the content. Much research shows that co-teaching and collaboration have some valuable benefits for K-12 students (Murawski, 2010; Murawski \& Swanson, 2001; Scruggs, Mastropieri, \& McDuffie, 2007), and that higher education faculty modeling of co-teaching practices in teacher preparation programmes can also influence the perceptions and skills of future educators (Bakken, Clark, \& Thompson, 1998; Bacharach, Heck, \& Dahlberg, 2008; Graziano \& Navarette, 2012; Hudson \& Glomb, 1997; Kluth \& Straut, 2003). While time was limited to 11 weeks, and other challenges existed (such as teaching on different nights), this study presents positive outcomes of the experience of two professors in co-teaching and collaborating as a first-time endeavor. These data add a small piece to the growing body of literature in support of ways faculty can work together in GE and SPE teacher preparation programmes (Kluth \& Straut, 2003). However, more research is needed to seek additional supports for faculty (despite heavy teaching loads and other duties) to combine university courses and to best achieve the intended outcomes of preparing GE and SPE teachers. Further research also needs to be conducted on the impact of this type of preparation on GE and SPE teachers, whether their practices in the field will indeed be more sophisticated given this opportunity to learn from higher education faculty engaged in co-teaching, and whether this knowledge and training will improve education for the children served. In looking toward the future about what coteaching and collaboration might look like, Friend (2015/2016) suggests GE and SPE professionals strive for parity and consider other dimensions of coteaching, acknowledging each teacher as being equally valued for his/her individual differences and contributions, thus "creating a classroom culture of acceptance, in which learning variations and strategies to address those variations 
are the norm" (p. 22).

\section{Acknowledgements}

Thanks to our Associate Dean, Dr. Diane Fazzi, and our college curriculum committee for establishing a collaborative teaching grant and the opportunity for us to pursue this project.

\section{References}

August, D., \& Shanahan, T. (2006). Developing literacy in second-language learners: Report of the National Literacy Panel on language-minority children and youth. Mahwah, NJ: Erlbaum.

Bacharach, N., Heck, T. W., \& Dahlberg, K. (2008). Co-teaching in higher education. Journal of College Teaching \& Learning, 5(3), 9-16.

Bakken, L., Clark, F. L., \& Thompson, J. (1998). Collaborative teaching: Many joys, some surprises, and a few worms. College Teaching, 46(4), 154-57.

Cook, L., \& Friend, M. (1995). Coteaching: Guidelines for creating effective practices. Focus on Exceptional Children, 28(3), 1-17.

Common Core State Standards Initiative. (2014). Common core standards initiative: preparing America's students for college and career. Retrieved from http:// www.corestandards.org/

Every Student Succeeds Act (ESSA) of 2015, Pub. L. No. 114-95, § 1177 (2015).

Fennick, E., \& Liddy, D. (2001). Responsibilities and preparation for collaborative teaching: Co- teachers' perspectives. Teacher Education and Special Education, $24,229-240$.

Friend, M., \& Cook, L. (2007). Interactions: Collaboration skills for school professionals. White Plains, NY: Longman.

Friend, M. (2015/2016). Welcome to Co-teaching 2.0, Educational Leadership, 16- 22.

Friend, M. (2014). Co-Teach! Creating and sustaining effective classroom partnerships in inclusive schools (2nd ed.). Greensboro, NC: Marilyn Friend, Inc.

Friend, M., Cook, L., Hurley-Chamberlain, D., \& Shamberger, C. (2010). Co- teaching: An illustration of the complexity of collaboration in special education. Journal of Educational and Psychological Consultation, 20, 9-27.

Graziano, K. J., \& Navarrete, L. A. (2012). Co-teaching in a teacher education classroom: Collaboration, compromise, and creativity. Issues in Teacher Education, 21(1), 109-126.

Hudson, P. \& Glomb, N. (1997). If it takes two to tango, why not teach both partners to dance? Collaboration instruction for all educators. Journal of Learning Disabilities, 30(4), 442-448.

Individuals with Disabilities Education Improvement Act (IDEIA, 2004). P. L.108 446.

Kluth, P., \& Straut, D. (2003). Do as we say and as we do: Teaching and modeling collaborative practice in the university classroom. Journal of Teacher Education, 54(3), 228-40.

Magiera, K., Smith, C.Z., Zigmond, N., \& Gebauer, K. (2005). Benefits of co- teaching in secondary mathematics classes. Teaching Exceptional Children, 37(3), 20-24.

Murawski, W. (2010). Collaborative teaching in elementary schools: Making the marriage work! Thousand Oaks, CA: Corwin. 
Vol. 4, No. $4 \quad$ Ricci et al.: Faculty Modeling Co-Teaching and Collaboration...

Murawski, W., \& Dieker, L. (2013). Leading the co-teaching dance: Leadership strategies to enhance team outcomes. Arlington, VA: Council for Exceptional Children.

Murawski, W. W., \& Swanson, H. L. (2001). A meta-analysis of co-teaching research: Where are the data? Remedial And Special Education, 22(5), 258-67.

No Child Left Behind (NCLB) Act of 2001, Pub. L. No. 107-110, § 115, Stat. 1425 (2002).

Scruggs, T. E., Mastropieri, M. A., \& McDuffie, K. A. (2007). Co-teaching in inclusive classrooms: A metasynthesis of qualitative research. Exceptional Children, 73(4), 392-416.

Snell, M.E., \& Janney, R. (2000). Teacher's guides to inclusive practices: Collaborative teaming. Baltimore, ME: Paul H. Brookes.

Strunk, K.O., \& McEachin, A. (2014). More than sanctions: Closing achievement gaps Through California's use of intensive technical assistance. Educational Evaluation and Policy Analysis, 36(3), 281-306.

Tröhler, D., Meyer, H.-D., Labaree, D. F., \& Hutt, E. L. (2014). Accountability: Antecedents, power, and processes. Teachers College Record, 116, 1-12.

Villa, R., Thousand, J., \& Nevin, A. (2013). A guide to co-teaching: New lessons and strategies to facilitate student learning (3rd Edition). Thousand Oaks, California: Corwin Press. 